\title{
Control of Cerebral Blood Flow by Blood Gases
}

\author{
James Duffin ${ }^{1,2,3,4 *}$, David J. Mikulis ${ }^{5}$ and Joseph A. Fisher ${ }^{1,2,3,4,6}$ \\ ${ }^{1}$ Department of Anesthesia and Pain Management, University of Toronto, Toronto, ON, Canada, ${ }^{2}$ Department of Physiology, \\ University of Toronto, Toronto, ON, Canada, ${ }^{3}$ Thornhill Research Inc., Toronto, ON, Canada, ${ }^{4}$ University Health Network, \\ Toronto, ON, Canada, ${ }^{5}$ Division of Neuroradiology Imaging, Joint Department of Medical Imaging, University Health Network, \\ Toronto, ON, Canada, ${ }^{6}$ Faculty of Medicine, Institute of Medical Science, University of Toronto, Toronto, ON, Canada
}

Cerebrovascular reactivity can be measured as the cerebrovascular flow response to a hypercapnic challenge. The many faceted responses of cerebral blood flow to combinations of blood gas challenges are mediated by its vasculature's smooth muscle and can be comprehensively described by a simple mathematical model. The model accounts for the blood flow during hypoxia, anemia, hypocapnia, and hypercapnia. The main hypothetical basis of the model is that these various challenges, singly or in combination, act via a common regulatory pathway: the regulation of intracellular hydrogen ion concentration. This regulation is achieved by membrane transport of strongly dissociated ions to control their intracellular concentrations. The model assumes that smooth muscle vasoconstriction and vasodilation and hence cerebral blood flow, are proportional to the intracellular hydrogen ion concentration. Model predictions of the cerebral blood flow responses to hypoxia, anemia, hypocapnia, and hypercapnia match the form of observed responses, providing some confidence that the theories on which the model is based have some merit.

Keywords: cerebral blood flow, mathematical model, hypercapnia, hypoxia, anemia, hypocapnia

\section{INTRODUCTION}

The mathematical model proposed here is concerned with the physiological mechanisms regulating cerebral blood flow (CBF) in response to anemia, hypoxia, and hypercapnia and hypocapnia. Cerebral blood flow increases in anemia (Brown et al., 1985; Borzage et al., 2016; Zheng et al., 2016); as well as during acute alterations in arterial blood gases (Willie et al., 2012) such as hypoxia (Cohen et al., 1967; Mardimae et al., 2012), and hypercapnia (Battisti-Charbonney et al., 2011). The model is tested by comparing its predictions to observations.

Cerebral blood flow is largely controlled by changes in the vascular resistance in parenchymal

Received: 10 December 2020 Accepted: 25 January 2021 Published: 18 February 2021

Citation:

Duffin J, Mikulis DJ and Fisher JA (2021) Control of Cerebral Blood Flow by Blood Gases.

Front. Physiol. 12:640075. doi: 10.3389/fphys.2021.640075 arterioles. The large pial arteries on the surface of the cortex contain multiple layers of vascular smooth muscle cells (Wei et al., 1980). These pial vessels branch into penetrating arterioles containing a single layer of vascular smooth muscle cells (Nishimura et al., 2007), and enter the cortical parenchyma, where micro vessels covered by pericytes but do not control microregional CBF (Hill et al., 2015). Vascular smooth muscle is the final CBF control effector in: (i) Autoregulation which mitigates against variations in brain perfusion pressure (Tan and Taylor, 2014; Tzeng and Ainslie, 2014), and (ii) Neurovascular Coupling which increases local blood flow 
in response to increased neuronal metabolic demand (Attwell et al., 2011, 2016; Phillips et al., 2016; Hosford and Gourine, 2019; Hoiland et al., 2020).

Acute changes in arterial blood gases also affect CBF, independently of these regulatory mechanisms (Willie et al., 2012). Hypoxia (Cohen et al., 1967; Mardimae et al., 2012) and hypercapnia (Battisti-Charbonney et al., 2011; Hoiland et al., 2019), as well as decreases in hemoglobin (anemia) (Borzage et al., 2016; Duffin et al., 2020) increase CBF, while hypocapnia decreases CBF (Battisti-Charbonney et al., 2011; Hoiland et al., 2019). It is the increase in CBF during hypercapnia that is the basis of cerebrovascular reactivity (CVR) testing.

In the presence of hypoxia and anemia, vascular tone decreases to increase $\mathrm{CBF}$ and maintain an adequate $\mathrm{O}_{2}$ supply (Duffin, 2020). Long term changes in CBF occur in chronic anemia (Brown et al., 1985) including sickle cell anemia (Bush et al., 2016), altitude acclimatization (Wolff, 2000) and chronic hypoxia (Powell and Fu, 2008), and are accompanied by a multitude of adaptive changes orchestrated via the HIF 1 alpha pathway (Poellinger and Johnson, 2004). Over the long term the cerebral vasculature remodels to provide larger diameter vessels and accommodate higher CBF (Hulbert et al., 2017).

Vascular smooth muscle tone depends on intracellular $\left[\mathrm{H}^{+}\right]$; contracting in alkalosis and relaxing in acidosis (Austin and Wray, 1993; Aalkjaer and Peng, 1997) to consequently alter CBF. Changes in intracellular $\left[\mathrm{H}^{+}\right]$alter intracellular $\left[\mathrm{Ca}^{2+}\right]$ (Swietach et al., 2013) and consequently smooth muscle tone (Boedtkjer, 2018), with the relaxation produced by hypercapnic acidosis, as in CVR testing, mediated by a reduction of $\left[\mathrm{Ca}^{2+}\right]$ (Peng et al., 1998), although, rapid acute acidification can cause a transient increase in intracellular $\left[\mathrm{Ca}^{2+}\right]$ that leads to contraction (Jensen et al., 1993).

Intracellular $\left[\mathrm{H}^{+}\right]$is the key intracellular regulated ion (Boedtkjer and Aalkjaer, 2012; Boedtkjer, 2018; Rasmussen and Boedtkjer, 2018); with a typical resting intracellular $\left[\mathrm{H}^{+}\right]$in vascular smooth muscle cells of about 50-80 nM/L (Boedtkjer et al., 2012). This regulation requires a net acid extrusion to maintain normal intracellular acid-base homeostasis, and it is this regulation that is challenged during CVR hypercapnia, producing a vasodilation and increased CBF (Kontos et al., 1977; Peng et al., 1998).

Stewart (Stewart, 1983; Hughes and Brain, 2013) has suggested an insightful approach to understanding acid-base changes in biological systems. In this system, intracellular $\left[\mathrm{H}^{+}\right]$is determined by $\mathrm{CO}_{2}$ tension, the balance of concentrations of the strongly dissociated ions (the strong ion difference [SID]), and the requirement for electroneutrality. Consequently, the regulation of intracellular $\left[\mathrm{H}^{+}\right]$depends on cell membrane ion exchangers (Aalkjaer, 1990; Hughes and Brain, 2013; Boedtkjer, 2018; Garneau et al., 2020), to control intracellular [SID]. These membrane ion exchangers are energy dependent (Garneau et al., 2020) so that reductions in $\mathrm{O}_{2}$ availability (Hoiland et al., 2016) (blood $\mathrm{O}_{2}$ content, $\mathrm{CaO}_{2}$ ) to the cerebral vasculature smooth muscles reduces the ability of these membrane ion exchangers to control intracellular [SID], and hence intracellular $\left[\mathrm{H}^{+}\right]$, smooth muscle tone and $\mathrm{CBF}$. Thus, changes in arterial $\mathrm{CO}_{2}$ tension $\left(\mathrm{PaCO}_{2}\right)$ override intracellular $\left[\mathrm{H}^{+}\right]$regulation to produce vasodilation and vasoconstriction. Similarly, decreases in $\mathrm{CaO}_{2}$ caused by decreases in arterial $\mathrm{O}_{2}$ tension $\left(\mathrm{PaO}_{2}\right.$, i.e., hypoxia) or hemoglobin concentration ([Hb] i.e., anemia) degrade the efficiency or capacity of membrane ion exchangers that control [SID] producing an increase in intracellular $\left[\mathrm{H}^{+}\right]$, which causes vasodilation and results in an increase in CBF. This model is pictured in Figure 1.

\section{MATERIALS AND METHODS}

The model equations are presented in the following assumptions using these symbols:

$\left[\mathrm{H}^{+}\right]=$intracellular hydrogen ion concentration $(\mathrm{nM} / \mathrm{L})$.

$\mathrm{PCO}_{2}=$ intracellular $\mathrm{CO}_{2}$ tension $=$ arterial $\mathrm{CO}_{2}$ tension (mmHg).

[SID] = intracellular [strongly dissociated cations] [strongly dissociated anions] ( $\mathrm{mM} / \mathrm{L})$.

$\mathrm{CBF}=$ cerebral blood flow $(\mathrm{ml} / \mathrm{min} / 100 \mathrm{ml})$.

$\mathrm{CaO}_{2}=\operatorname{arterial~} \mathrm{O}_{2}$ concentration $/$ content $(\mathrm{ml} / \mathrm{ml})$.

The equation parameters were empirically derived from observed responses to the various disturbances.

Assumption 1: Cerebrovascular smooth muscle intracellular $\left[\mathrm{H}^{+}\right]$is a function of $\mathrm{PCO}_{2}$ and [SID] (Stewart, 1983) (see Appendix):

$$
\left[\mathrm{H}^{+}\right](\mathrm{nM} / \mathrm{L})=\text { Function of }\left\{\mathrm{PCO}_{2},[\mathrm{SID}]\right\}
$$

Assumption 2: $\left[\mathrm{H}^{+}\right]$is regulated by a feedback alteration of [SID] proportional to the deviation of $\left[\mathrm{H}^{+}\right]$from its regulated value of $\left[\mathrm{H}^{+}\right] n=40 \mathrm{nM} / \mathrm{L}$ according to the following eq. 2 , which assumes that maximum vasoconstriction occurs at $\mathrm{PCO}_{2}=10 \mathrm{mmHg}$ and $[\mathrm{SID}]=5.5 \mathrm{mM} / \mathrm{L}$. Figure 2 outlines the operation of this regulator.

$$
[\mathrm{SID}]=5.5+\text { Gain }^{*}\left(\left(\left[\mathrm{H}^{+}\right]-40\right)+2\right)
$$

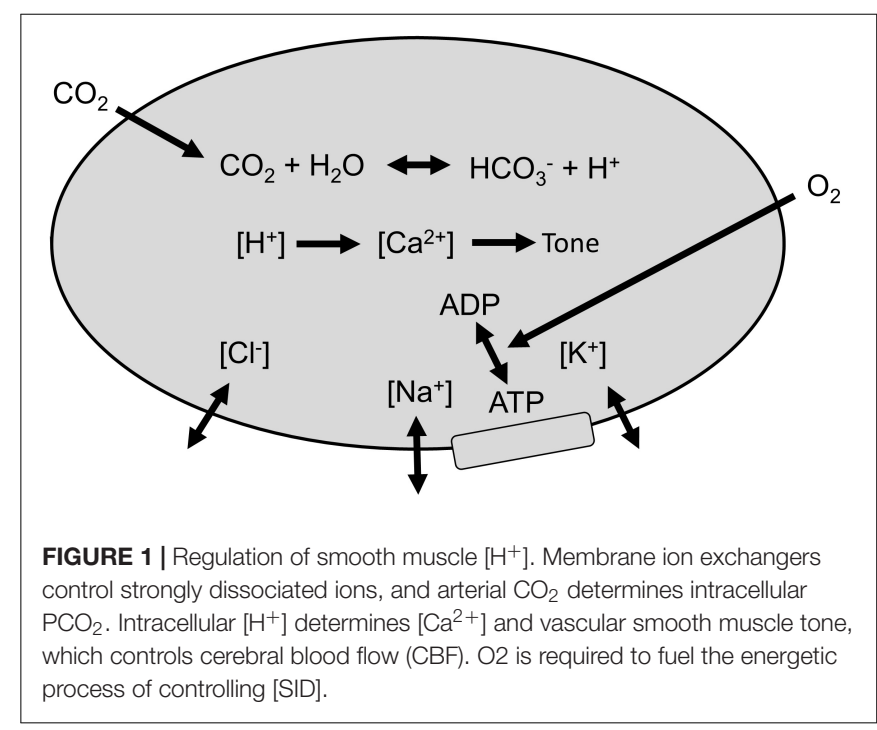




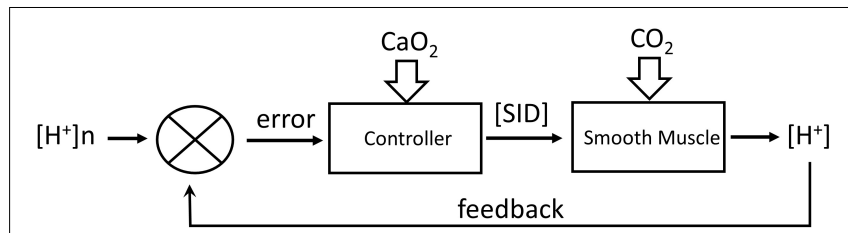

FIGURE 2 | Regulation of $\left[\mathrm{H}^{+}\right]$by feedback control of [SID] by transmembrane transport of strongly dissociated ions. $\mathrm{CO}_{2}$ acts as a disturbance to the system. $\mathrm{CaO}_{2}$ acts to alter the controller gain.

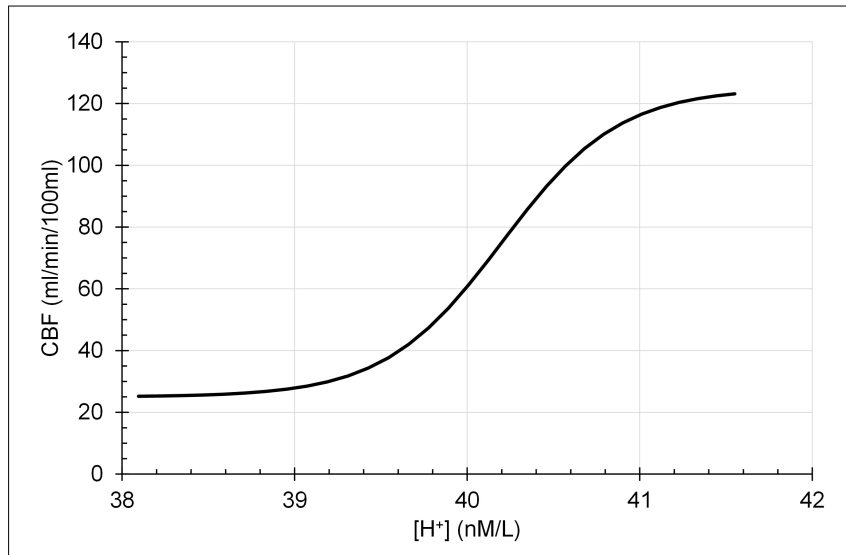

FIGURE 3 | Cerebral blood flow (CBF) is a sigmoidal function of intracellular $\left[\mathrm{H}^{+}\right]$.

Assumption 3: Smooth muscle tone is assumed to be limited to a maximum vasoconstriction and vasodilation so that $\mathrm{CBF}$ is a sigmoid function of intracellular $\left[\mathrm{H}^{+}\right]$according to the following eq. 3, which is illustrated in Figure 3:

$$
\mathrm{CBF}=25+100 /\left(1+\exp \left(-\left(\left[\mathrm{H}^{+}\right]-40.2\right) / 0.34\right)\right)
$$

Assumption 4: The regulation of $\left[\mathrm{H}^{+}\right]$by [SID] is oxygen dependent with the Gain of eq. 2 a function of arterial oxygen content, $\mathrm{CaO}_{2}$, according to eq. 4 , as illustrated in Figure 4.

$$
\text { Gain }=12.6-0.5 / \mathrm{CaO}_{2}
$$

$\mathrm{CaO}_{2}$ is calculated from $\mathrm{PaCO}_{2}, \mathrm{PaO}_{2}$, and $[\mathrm{Hb}]$ using previously published equations (Duffin, 2005; Balaban et al., 2013).

The system equations are solved using an iterative approach (LabVIEW, National Instruments, Austin, TX, United States) outlined in the block diagram of Figure 5.

\section{RESULTS}

The model performance was assessed by its $\mathrm{CBF}$ responses to changes in $\mathrm{PCO}_{2}, \mathrm{PO}_{2}$ and $[\mathrm{Hb}]$ as shown in the following figures (Figures 6-8), which compare the model responses with examples of observed responses.

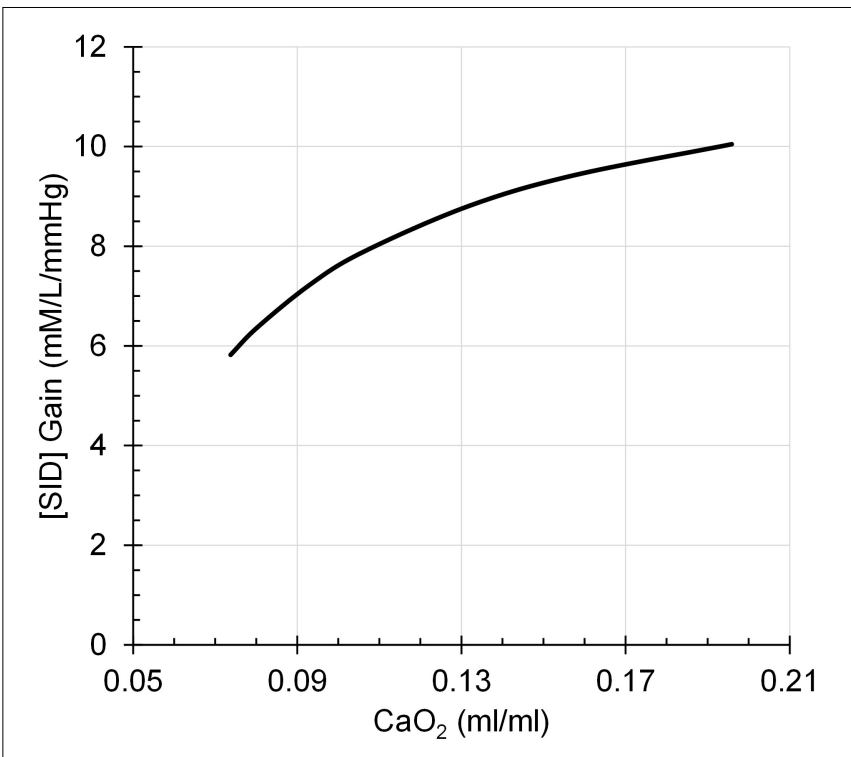

FIGURE 4 | [SID] Gain decreases to a progressively greater degree as $\mathrm{CaO}_{2}$ declines in a rectangular hyperbolic function.

\section{DISCUSSION}

The model predictions for $\mathrm{CBF}$ responses match the form of the observed responses, providing some confidence that the theories on which the model was based are realistic. Of course, such a model does not prove the theories are correct, merely that they are feasible physiological mechanisms, and the interaction of the flow determinants are generally aligned to that of the model.

It must be emphasised that the model does not attempt to accurately predict the experimental examples provided but is a generic prediction of the form of the responses to test the hypotheses. For example, the midpoint of the sigmoidal response to $\mathrm{CO}_{2}$ from a TCD experiment in Figure 6 is lower than that of the model response. However, it is not beyond the bounds of observed midpoints in other experiment using different methods. For example, the midpoints in the TCD experiments (means of $35-36 \mathrm{mmHg}$ ) differ from those derived from the vascular resistance which varied over a range of 38$48 \mathrm{mmHg}$ (Duffin et al., 2018). A similar observation may be made for the responses to $[\mathrm{Hb}]$ in Figure 8 where the model responses exhibit considerable curvature as $[\mathrm{Hb}]$ decreases compared to the experimental observations. We note that there is considerable variability in the experimental observations, and while the authors chose to fit a linear response, the data indicates that curvature is present, as we showed in Duffin et al. (2020). Another confounding factor in the experimental observations is the variability of $\mathrm{PCO}_{2}$ in the experiments where $\mathrm{PCO}_{2}$ was uncontrolled compared to the model where isocapnia was maintained. In summary, there is no doubt that the model can be improved by adjusting the parameters and the relations used, such as the linear one between $[\mathrm{SID}]$ and $\left[\mathrm{H}^{+}\right]$which is almost certainly a simplification and awaits experimental measurements. 


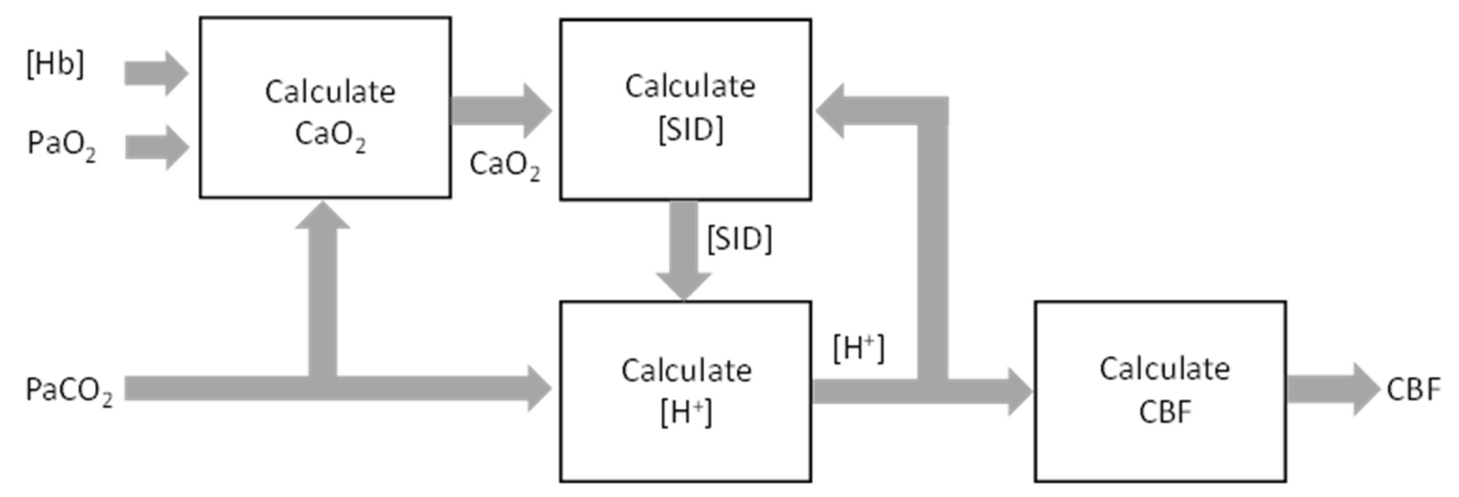

FIGURE 5 | Implementation block diagram of the feedback control of cerebral blood flow (CBF) by $\mathrm{PaCO}_{2}, \mathrm{PaO}_{2}$, and [Hb]
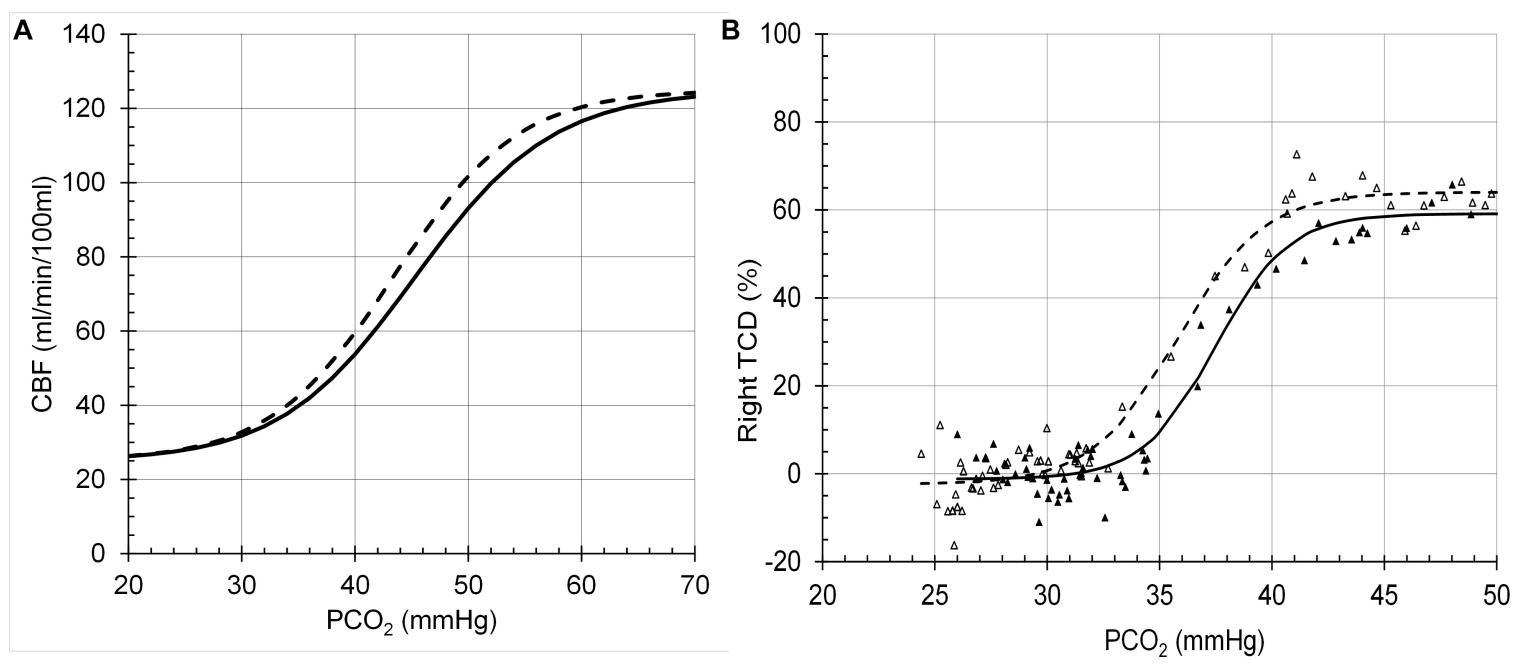

FIGURE 6 | Cerebral blood flow (CBF) responses to $\mathrm{PCO}_{2}$ at $\mathrm{PO}_{2}=150 \mathrm{mmHg}$ (solid line) and $\mathrm{PO}_{2}=50$ (dashed line). (A) Model response. (B) Example transcranial Doppler (TCD) measurements of middle cerebral artery blood flow velocities (Battisti-Charbonney et al., 2011).
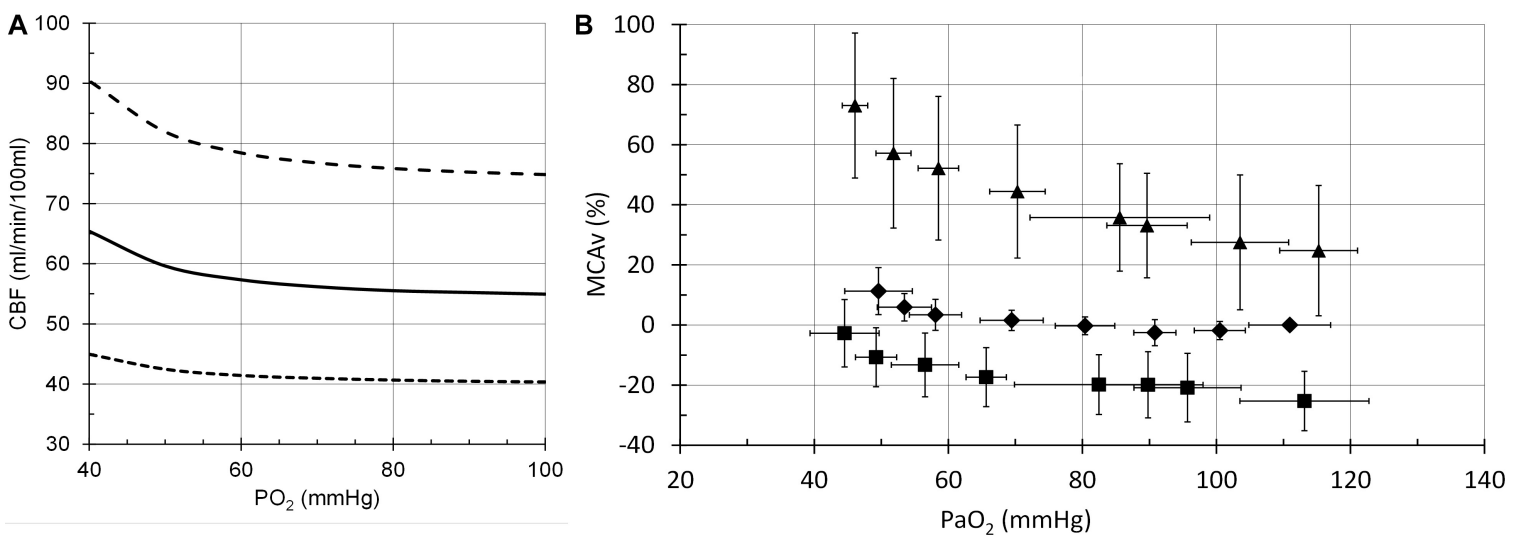

FIGURE 7 | Cerebral blood flow (CBF) responses to $\mathrm{PO}_{2}$. (A) Model responses at $\mathrm{PCO}_{2}=35 \mathrm{mmHg}$ (dotted line), $\mathrm{PCO} 2=40 \mathrm{mmHg}$ (solid line) and $\mathrm{PCO}_{2}=50 \mathrm{mmHg}$ (dashed line). (B) Example transcranial Doppler (TCD) measurements of middle cerebral artery blood flow velocities at $\mathrm{PCO}=30 \mathrm{mmHg}$ (squares), $\mathrm{PCO}_{2}=40 \mathrm{mmHg}$ (diamonds) and $\mathrm{PCO}_{2}=50$ mmHg (triangles) (Mardimae et al., 2012). 

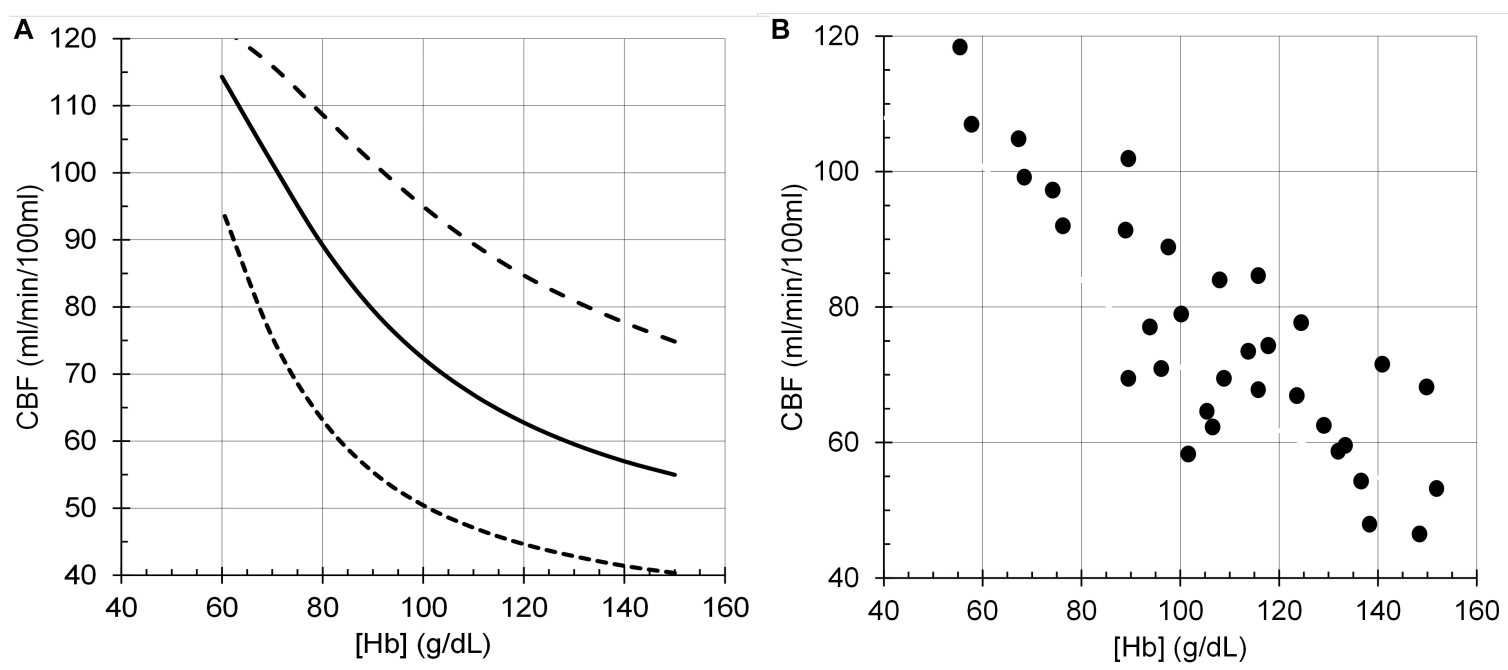

FIGURE 8 | Cerebral blood flow (CBF) responses to anemia ([Hb]). (A) Model responses at $\mathrm{PCO}_{2}=35 \mathrm{mmHg}(\mathrm{dotted}$ line), $\mathrm{PCO} 2=40 \mathrm{mmHg}(\mathrm{solid}$ line) and $\mathrm{PCO}_{2}=50 \mathrm{mmHg}$ (dashed line), and $\mathrm{PO}_{2}=100 \mathrm{mmHg}$. (B) Data from young end-stage renal disease adults replotted from Figure 1B of Zheng et al. (2016).

There are several assumptions underlying the model, and, as reviewed in the introduction, some are supported by experimental evidence. That cerebrovascular smooth muscle attempts to maintain a constant intracellular $\left[\mathrm{H}^{+}\right]$by some regulatory process appears to be supported (Boedtkjer, 2018). Furthermore, that $\left[\mathrm{H}^{+}\right]$acts via alterations in $\left[\mathrm{Ca}^{2+}\right]$ to control vascular smooth muscle tone and consequently CBF also appears to be substantiated (Aalkjaer and Peng, 1997). The physico-chemical theory of acidbase described by Stewart (Stewart, 1981) and illustrated in Hughes and Brain (2013) dictates that intracellular $\left[\mathrm{H}^{+}\right]$and bicarbonate $\left[\mathrm{HCO}_{3}{ }^{-}\right]$are dependent variables, with $\mathrm{CO}_{2}$ and [SID] independent variables that determine them. Therefore, the model assumption that $\left[\mathrm{H}^{+}\right]$is regulated by controlling [SID] in the face of a $\mathrm{CO}_{2}$ disturbance is an obvious conclusion. That [SID] must be adjusted by membrane transport processes is well known (Garneau et al., 2020).

The simple equation proposed to describe this regulation process is one of many that could be used to describe the relation between [SID] and the error signal, deviation of $\left[\mathrm{H}^{+}\right]$ from a normal resting value. The equation form assumes that maximum vasoconstriction occurs at the hypocapnic limit of vasoconstriction $\left(\mathrm{PCO}_{2}=10 \mathrm{mmHg}\right.$ where $[\mathrm{SID}]=5.5 \mathrm{mM} / \mathrm{L}$ attempting to restore $\left[\mathrm{H}^{+}\right]$to $40 \mathrm{nM} / \mathrm{L}$ ). This assumption has the result that at a normal resting $\mathrm{PCO}_{2}$ of $40 \mathrm{mmHg}$ the regulation of [SID] is active and consequently subject to degradation by a lack of $\mathrm{O}_{2}$.

The assumption that a decrease of $\mathrm{CaO}_{2}$ affects intracellular $\left[\mathrm{H}^{+}\right]$by degrading the [SID] regulation is a major hypothesis of the model and is testable. That $\mathrm{CBF}$ is related to $\mathrm{CaO}_{2}$, whether changed by anemia or hypoxia is well documented and the subject of a previous model (Duffin, 2020). Furthermore, it was previously demonstrated that brain tissue $\mathrm{PO}_{2}$ was not a viable choice as a sensed variable controlling CBF (Duffin et al., 2020). Consequently, $\mathrm{CaO}_{2}$ was the obvious choice of variable to represent a decreased $\mathrm{O}_{2}$ supply affecting the supply of energy to the membrane transporters of strongly dissociated ions thereby degrading the $[\mathrm{SID}]$ regulation of $\left[\mathrm{H}^{+}\right]$. However, there does not currently appear to be supportive experimental evidence for this assumption, and it requires investigation.

Other mechanisms by which $\mathrm{CaO}_{2}$ may change $\mathrm{CBF}$ involving nitric oxide (NO) have been proposed. Some (Hoiland et al., 2020) are linked to neurovascular coupling control of CBF (Attwell et al., 2011) rather than the control of blood $\mathrm{O}_{2}$ supply. Others involve release of NO from red blood cells (Hoiland et al., 2016) or endothelial cells (Iadecola, 1992; Kisler et al., 2017). However, experiments show that NO does not appear to be involved in responses to changes in blood gases (White et al., 1998; Ide et al., 2007). Furthermore, these mechanisms for $\mathrm{CBF}$ control independent of $\mathrm{CO}_{2}$, whether involving $\mathrm{NO}$ or not, do not agree with the observations of the interaction of $\mathrm{CaO}_{2}$ and $\mathrm{CO}_{2}$ in the control of CBF. For example, in hypocapnia, where vasoconstriction lowers $\mathrm{CBF}$, a decrease in $\mathrm{CaO}_{2}$ would be expected to increase $\mathrm{CBF}$ at least as much as is observed in normocapnia, but does not (Mardimae et al., 2012). The model proposed does so, exhibiting the interaction between $\mathrm{CaO}_{2}$ and $\mathrm{CO}_{2}$ observed (Figure 5).

\section{CONCLUSION}

This model can be used to predict the effects of hypoxia, hypercapnia and anemia, alone and in combination, on CBF. It therefore has practical usefulness for intensive care and intraoperative management where these conditions apply, as well as for drugs that affect carbonic acid dissociation and elimination, and shift the oxyhemoglobin dissociation curve.

The hypothetical basis of the model is not only supported in part by the experimental evidence used in its formulation, but also by the success of the model predictions of experimental observations. Thus, the hypothesized mechanisms merit 
consideration as realistic possibilities, deserving of experimental investigation to determine their correctness. We suggest that the physiological mechanism described in this model for the response to $\mathrm{CO}_{2}$ has widespread application as a general principle. It has already been used to describe the responses of the carotid body glomus cells to $\mathrm{CO}_{2}$ (Duffin, 2020) and may also be applicable to the central chemoreception of $\mathrm{CO}_{2}$ (Guyenet et al., 2019). It is an aspect of a physioc-chemical view of acid-base control pioneered by Stewart (1981) that should enable a better understanding of the processes involved in sensing $\mathrm{CO}_{2}$ and the effects of disturbances in energy supply and external $\mathrm{CO}_{2}$ on the process. We believe that such an increased understanding will impact research in this field to further characterise the mechanisms involved which in turn may inspire intervention opportunities that apply to clinical care.

\section{DATA AVAILABILITY STATEMENT}

The raw data supporting the conclusions of this article will be made available by the authors, without undue reservation.

\section{REFERENCES}

Aalkjaer, C. (1990). Regulation of intracellular $\mathrm{pH}$ and its role in vascular smooth muscle function. J. Hypertens. 8, 197-206. doi: 10.1097/00004872-19900300000001

Aalkjaer, C., and Peng, H.-L. (1997). pH and smooth muscle. Acta Physiol. Scand. $161,557-566$.

Attwell, D., Buchan, A. M., Charpak, S., Lauritzen, M., Macvicar, B. A., and Newman, E. A. (2011). Glial and neuronal control of brain blood flow. Nature 468, 232-243. doi: 10.1038/nature09613

Attwell, D., Mishra, A., Hall, C. N., O’Farrell, F. M., and Dalkara, T. (2016). What is a pericyte? J. Cereb. Blood Flow Metab. 36, 451-455. doi: 10.1177/ $0271678 \times 15610340$

Austin, C., and Wray, S. (1993). Extracellular pH signals affect rat vascular tone by rapid transduction into intracellular $\mathrm{pH}$ changes. J. Physiol. 466, 1-8.

Balaban, D. Y., Duffin, J., Preiss, D., Mardimae, A., Vesely, A., Slessarev, M., et al. (2013). The in-vivo oxyhaemoglobin dissociation curve at sea level and high altitude. Respir. Physiol. Neurobiol. 186, 45-52. doi: 10.1016/j.resp.2012.12. 011

Battisti-Charbonney, A., Fisher, J., and Duffin, J. (2011). The cerebrovascular response to carbon dioxide in humans. J. Physiol. 589, 3039-3048. doi: 10.1113/ jphysiol.2011.206052

Boedtkjer, E. (2018). Acid-base regulation and sensing: accelerators and brakes in metabolic regulation of cerebrovascular tone. J. Cereb. Blood Flow Metab. 38, 588-602. doi: $10.1177 / 0271678 \times 17733868$

Boedtkjer, E., and Aalkjaer, C. (2012). Intracellular $\mathrm{pH}$ in the resistance vasculature: regulation and functional implications. J. Vasc. Res. 49, 479-496. doi: 10.1159/ 000341235

Boedtkjer, E., Damkier, H. H., and Aalkjaer, C. (2012). NHE1 knockout reduces blood pressure and arterial media/lumen ratio with no effect on resting $\mathrm{pH}(\mathrm{i})$ in the vascular wall. J. Physiol. 590, 1895-1906. doi: 10.1113/jphysiol.2011.22 7132

Borzage, M. T., Bush, A. M., Choi, S., Nederveen, A. J., Václavù, L., Coates, T. D., et al. (2016). Predictors of cerebral blood flow in patients with and without anemia. J. Appl. Physiol. 120, 976-981. doi: 10.1152/japplphysiol.00994.2015

Brown, M. M., Wade, J. P., and Marshall, J. (1985). Fundamental importance of arterial oxygen content in the regulation of cerebral blood flow in man. Brain 108(Pt 1), 81-93. doi: 10.1093/brain/108.1.81

Bush, A. M., Borzage, M. T., Choi, S., Vaclavu, L., Tamrazi, B., Nederveen, A. J., et al. (2016). Determinants of resting cerebral blood flow in sickle cell disease. Am. J. Hematol. 91, 912-917. doi: 10.1002/ajh.24441

\section{ETHICS STATEMENT}

Ethical review and approval was not required for the study on human participants in accordance with the Local Legislation and Institutional Requirements. The patients/participants provided their written informed consent to participate in this study.

\section{AUTHOR CONTRIBUTIONS}

JD: conception and programming. JD, JF, and DM: drafting and revising of the article and final approval of the manuscript. All authors contributed to the article and approved the submitted version.

\section{ACKNOWLEDGMENTS}

The authors thank Thornhill Research Inc. for support.

Cohen, P. J., Alexander, S. C., Smith, T. C., Reivich, M., and Wollman, H. (1967). Effects of hypoxia and normocarbia on cerebral blood flow and metabolism in conscious man. J. Appl. Physiol. 23, 183-189. doi: 10.1152/jappl.1967.23.2.183

Duffin, J. (2005). Role of acid-base balance in the chemoreflex control of breathing. J. Appl. Physiol. 99, 2255-2265. doi: 10.1152/japplphysiol.00640.2005

Duffin, J. (2020). Fail-safe aspects of oxygen supply. J. Physiol. 598, 4859-4867. doi: 10.1113/jp280301

Duffin, J., Hare, G. M. T., and Fisher, J. A. (2020). A mathematical model of cerebral blood flow control in anaemia and hypoxia. J. Physiol. 598, 717-730. doi: $10.1113 /$ jp279237

Duffin, J., Sobczyk, O., Mcketton, L., Crawley, A., Poublanc, J., Venkatraghavan, L., et al. (2018). Cerebrovascular Resistance: The Basis of Cerebrovascular Reactivity. Front. Neurosci. 12:409. doi: 10.3389/fnins.2018.00409

Garneau, A. P., Slimani, S., Fiola, M. J., Tremblay, L. E., and Isenring, P. (2020). Multiple facets and roles of $\mathrm{Na}+-\mathrm{K}+-\mathrm{Cl}-$ cotransport: mechanisms and therapeutic implications. Physiology 35, 415-429. doi: 10.1152/physiol.00012. 2020

Guyenet, P. G., Stornetta, R. L., Souza, G. M. P. R., Abbott, S. B. G., Shi, Y., and Bayliss, D. A. (2019). The retrotrapezoid nucleus: central chemoreceptor and regulator of breathing automaticity. Trend. Neurosci. 42, 807-824. doi: 10.1016/j.tins.2019.09.002

Hill, R. A., Tong, L., Yuan, P., Murikinati, S., Gupta, S., and Grutzendler, J. (2015). Regional blood flow in the normal and ischemic brain is controlled by arteriolar smooth muscle cell contractility and not by capillary pericytes. Neuron 87, 95-110. doi: 10.1016/j.neuron.2015.06.001

Hoiland, R. L., Bain, A. R., Rieger, M. G., Bailey, D. M., and Ainslie, P. N. (2016). Hypoxemia, oxygen content, and the regulation of cerebral blood flow. Am. J. Physiol. Regul. Integr. Comp. Physiol. 310, R398-R413.

Hoiland, R. L., Caldwell, H. G., Howe, C. A., Nowak-Flück, D., Stacey, B. S., Bailey, D. M., et al. (2020). Nitric oxide is fundamental to neurovascular coupling in humans. J. Physiol. 598, 4927-4939. doi: 10.1113/jp280162

Hoiland, R. L., Fisher, J. A., and Ainslie, P. N. (2019). Regulation of the cerebral circulation by arterial carbon dioxide. Compr. Physiol. 9, 1101-1154. doi: 10.1002/cphy.c180021

Hosford, P. S., and Gourine, A. V. (2019). What is the key mediator of the neurovascular coupling response? Neurosci. Biobehav. Rev. 96, 174-181. doi: 10.1016/j.neubiorev.2018.11.011

Hughes, R., and Brain, M. J. (2013). A simplified bedside approach to acidbase: fluid physiology utilizing classical and physicochemical approaches. Anaesth. Intens. Care Med. 14, 445-452. doi: 10.1016/j.mpaic.2013. 07.013 
Hulbert, M. L., Guilliams, K. P., Fields, M. E., Bijlani, P., Ragan, D. K., Eldeniz, C., et al. (2017). Normalization of cerebral hemodynamics after hematopoietic stem cell transplant in children with sickle cell anemia. Blood 130, 2245-2245.

Iadecola, C. (1992). Does nitric oxide mediate the increases in cerebral blood flow elicited by hypercapnia? Proc. Natl. Acad. Sci. U.S.A. 89, 3913-3916. doi: 10.1073/pnas.89.9.3913

Ide, K., Worthley, M., Anderson, T., and Poulin, M. J. (2007). Effects of the nitric oxide synthase inhibitor L-NMMA on cerebrovascular and cardiovascular responses to hypoxia and Hypercapnia in humans. J. Physiol. 584, 321-332. doi: 10.1113/jphysiol.2007.138206

Jensen, P. E., Hughes, A., Boonen, H. C., and Aalkjaer, C. (1993). Force, membrane potential, and $[\mathrm{Ca} 2+] \mathrm{i}$ during activation of rat mesenteric small arteries with norepinephrine, potassium, aluminum fluoride, and Phorbol ester. Effects of changes in pHi. Circ. Res. 73, 314-324. doi: 10.1161/01.res.73.2.314

Kisler, K., Nelson, A. R., Montagne, A., and Zlokovic, B. V. (2017). Cerebral blood flow regulation and neurovascular dysfunction in Alzheimer disease. Nat. Rev. Neurosci. 18, 419-434. doi: 10.1038/nrn.2017.48

Kontos, H. A., Wei, E. P., Raper, A. J., and Patterson, J. L. Jr. (1977). Local mechanism of CO2 action of cat pial arterioles. Stroke 8, 226-229. doi: 10.1161/ 01.str.8.2.226

Mardimae, A., Balaban, D. Y., Machina, M. A., Han, J. S., Katznelson, R., Minkovich, L. L., et al. (2012). The interaction of carbon dioxide and hypoxia in the control of cerebral blood flow. Pflugers Arch. 464, 345-351.

Nishimura, N., Schaffer, C. B., Friedman, B., Lyden, P. D., and Kleinfeld, D. (2007). Penetrating arterioles are a bottleneck in the perfusion of neocortex. Proc. Natl. Acad. Sci. U.S.A. 104, 365-370. doi: 10.1073/pnas.0609551104

Peng, H. L., Ivarsen, A., Nilsson, H., and Aalkjaer, C. (1998). On the cellular mechanism for the effect of acidosis on vascular tone. Acta Physiol. Scand. 164, 517-525. doi: 10.1111/j.1365-201x.1998.tb10701.x

Phillips, A. A., Chan, F. H., Zheng, M. M., Krassioukov, A. V., and Ainslie, P. N. (2016). Neurovascular coupling in humans: physiology, methodological advances and clinical implications. J. Cereb. Blood Flow Metab. 36, 647-664. doi: $10.1177 / 0271678 \times 15617954$

Poellinger, L., and Johnson, R. S. (2004). HIF-1 and hypoxic response: the plot thickens. Curr. Opin. Genet. Dev. 14, 81-85. doi: 10.1016/j.gde.2003.12.006

Powell, F. L., and Fu, Z. (2008). HIF-1 and ventilatory acclimatization to chronic hypoxia. Respir. Physiol. Neurobiol. 164, 282-287. doi: 10.1016/j.resp.2008.07. 017

Rasmussen, J. K., and Boedtkjer, E. (2018). Carbonic anhydrase inhibitors modify intracellular $\mathrm{pH}$ transients and contractions of rat middle cerebral arteries during CO2/HCO3(-) fluctuations. J. Cereb. Blood Flow Metab. 38, 492-505. doi: $10.1177 / 0271678 \times 17699224$
Stewart, P. A. (1981). How to Understand Acid - Base: A Quantitative Acid - Base Primer for Biology and Medicine. New York, NY: Elsevier.

Stewart, P. A. (1983). Modern quantitative acid-base chemistry. Can. J. Physiol. Pharmacol. 61, 1444-1461. doi: 10.1139/y83-207

Swietach, P., Youm, J. B., Saegusa, N., Leem, C. H., Spitzer, K. W., and VaughanJones, R. D. (2013). Coupled $\mathrm{Ca} 2+/ \mathrm{H}+$ transport by cytoplasmic buffers regulates local $\mathrm{Ca} 2+$ and $\mathrm{H}+$ ion signaling. Proc. Natl. Acad. Sci. U.S.A. 110, E2064-E2073.

Tan, C. O., and Taylor, J. A. (2014). Integrative physiological and computational approaches to understand autonomic control of cerebral autoregulation. Exper. Physiol. 99, 3-15. doi: 10.1113/expphysiol.2013.072355

Tzeng, Y. C., and Ainslie, P. N. (2014). Blood pressure regulation IX: cerebral autoregulation under blood pressure challenges. Eur. J. Appl. Physiol. 114, 545-559. doi: 10.1007/s00421-013-2667-y

Wei, E. P., Kontos, H. A., and Patterson, J. L. Jr. (1980). Dependence of pial arteriolar response to hypercapnia on vessel size. Am. J. Physiol. 238, 697-703.

White, R. P., Deane, C., Vallance, P., and Markus, H. S. (1998). Nitric oxide synthase inhibition in humans reduces cerebral blood flow but not the hyperemic response to hypercapnia. Stroke 29, 467-472. doi: 10.1161/01.str.29. 2.467

Willie, C. K., Macleod, D. B., Shaw, A. D., Smith, K. J., Tzeng, Y. C., Eves, N. D., et al. (2012). Regional brain blood flow in man during acute changes in arterial blood gases. J. Physiol. 590, 3261-3275. doi: 10.1113/jphysiol.2012.228551

Wolff, C. B. (2000). Cerebral blood flow and oxygen delivery at high altitude. High. Alt. Med. Biol. 1, 33-38. doi: 10.1089/152702900320667

Zheng, G., Wen, J., Yu, W., Li, X., Zhang, Z., Chen, H., et al. (2016). Anemia rather than hypertension contributes to cerebral hyperperfusion in young adults undergoing hemodialysis: a phase contrast MRI study. Sci. Rep. 6:22346.

Conflict of Interest: JF and DM have equity in Thornhill Medical Inc. JD receives salary support from Thornhill Medical Inc. Thornhill Medical Inc. provided no other support for the study.

The authors declare that the research was conducted in the absence of any commercial or financial relationships that could be construed as a potential conflict of interest.

Copyright (c) 2021 Duffin, Mikulis and Fisher. This is an open-access article distributed under the terms of the Creative Commons Attribution License (CC BY). The use, distribution or reproduction in other forums is permitted, provided the original author(s) and the copyright owner(s) are credited and that the original publication in this journal is cited, in accordance with accepted academic practice. No use, distribution or reproduction is permitted which does not comply with these terms. 


\section{APPENDIX}

The acid-base control of intracellular $\left[\mathrm{H}^{+}\right]$was calculated using an iterative approach that solved eq. $1-4$ to enforce electrical neutrality by minimizing $\mathrm{R}$.

$$
\begin{aligned}
& {\left[\mathrm{HCO}_{3}{ }^{-}\right]=\mathrm{KC} * \mathrm{PCO} 2 /\left[\mathrm{H}^{+}\right]} \\
& {\left[\mathrm{CO}_{3}{ }^{2-}\right]=\mathrm{K}^{*}\left[\mathrm{HCO}^{2-}\right] /\left[\mathrm{H}^{+}\right]} \\
& {\left[\mathrm{OH}^{-}\right]=\mathrm{Kw} /\left[\mathrm{H}^{+}\right]} \\
& \mathrm{R}=[\mathrm{SID}]+\left[\mathrm{H}^{+}\right]--\left[\mathrm{HCO}_{3}{ }^{-}\right]-2^{*}\left[\mathrm{CO}_{3}{ }^{2-}\right]--\left[\mathrm{OH}^{-}\right]
\end{aligned}
$$

where:

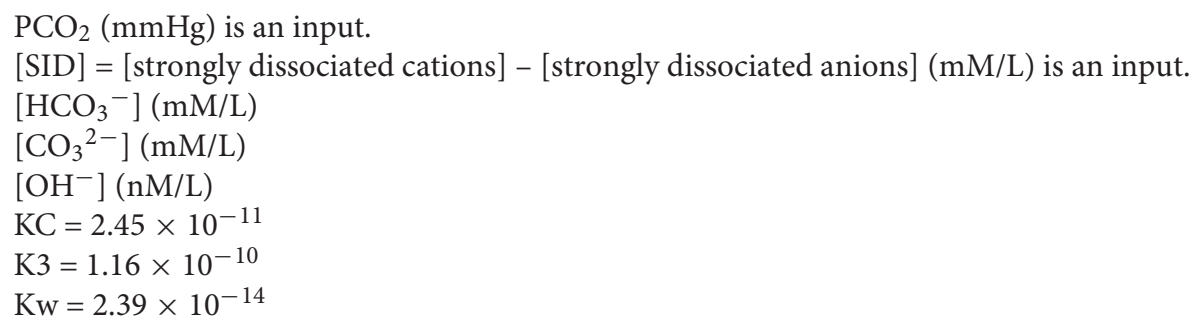

